\title{
Ensino remoto e a pandemia da Covid-19: experiências e aprendizados
}

\author{
Jurandir Moura Dutra ${ }^{1}$ \\ Ana Flávia de Moraes Moraes ${ }^{2}$ \\ Maria da Glória Vitório Guimarães ${ }^{3}$
}

\section{RESUMO}

Este artigo propõe-se a analisar os aspectos que se constituíram a partir da necessidade de adaptação das atividades presenciais para atividades remotas na Universidade Federal do Amazonas (UFAM) durante o distanciamento social causado pela COVID-19. A estratégia utilizada pela UFAM concentrou-se em fornecer acesso temporário aos métodos de ensinoaprendizagem de uma maneira que fosse rápida. Os pesquisadores analisaram a percepção dos alunos matriculados em três disciplinas, componentes da matriz curricular do curso de Administração. Todas foram ofertadas por meio do Google Classroom, dispondo de aulas síncronas - mediadas pelo Google Meet -, cujo planejamento oscilou em torno de $40 \%$ a $50 \%$ da carga horária matricial. Ademais, foram adotados grupos de WhatsApp com o intuito de se atingir uma comunicação mais rápida e eficiente. Pôde-se identificar um ambiente de cooperação entre os discentes; muitos relatos positivos quanto aos docentes e expectativas atendidas. Além disso, um elevado índice de aprovação também foi observado. Destaca-se que existem problemas e dificuldades a serem resolvidos em relação à utilização das tecnologias no processo educacional, porém é inegável que tais tecnologias contribuíram com práticas mais colaborativas e relações mais horizontais entre professores e alunos no Ensino Superior.

Palavras-chave: Práticas Colaborativas; Docente On-line; Tecnologias Digitais Interativas.

\footnotetext{
${ }^{1}$ jurandirdutra@ufam.edu.br - Universidade Federal do Amazonas

2 anaflavia@ufam.edu.br - Universidade Federal do Amazonas

${ }^{3}$ gloriavitorio@ufam.edu.br - Universidade Federal do Amazonas
} 


\section{Remote teaching and the Covid-19 pandemic: experiences and lessons learned}

\section{ABSTRACT}

This article aims to analyze the aspects that were formed from the need to adapt face-to-face activities to remote activities at the Federal University of Amazonas (UFAM) during the social distance caused by COVID-19. The strategy used by UFAM focused on providing temporary access to teaching-learning methods in a quick way. The researchers analyzed the perception of students enrolled in three subjects, components of the curriculum of the Administration course. All were offered through Google Classroom, with synchronous classes mediated by Google Meet, whose planning ranged around $40 \%$ to $50 \%$ of the matrix workload. In addition, WhatsApp groups were adopted to achieve faster and more efficient communication. It was possible to identify an environment of cooperation among the students; many positive reports regarding the teachers and expectations met. In addition, a high approval rating was also observed. It is noteworthy that there are problems and difficulties to be resolved in relation to the use of technologies in the educational process, but it is undeniable that such technologies have contribute to more collaborative practices and more horizontal relationships between teachers and students in Higher Education.

Keywords: Collaborative Practices. Online Teacher. Interactive Digital Technologies. 
No ano de 2020, o mundo é paralisado por uma pandemia. Um vírus altamente contagioso e razoavelmente letal provoca uma transformação inimaginável na sociedade do 24/7 - vinte quatro horas por dia e sete dias por semana, que não pode parar, que precisa produzir, que faz tudo para ganhar mais e mais (SARAIVA; TRAVERSINI; LOCKMANN, 2020). A pandemia da Covid-19 foi declarada pela Organização Mundial de Saúde (OMS) em 11 de março de 2020 (OPAS, 2020). 0 Brasil registrou o primeiro caso em 26 de fevereiro de 2020 na cidade de São Paulo; em 13 de março de 2020, foi a vez de Manaus. Nesse mesmo dia de março, a Universidade Federal do Amazonas interrompeu as atividades presenciais por meio da Portaria GR $N^{\circ} 626 / 2020$. Naquele momento, a previsão era de retomada das atividades em 15 dias, contudo, em 26 de março de 2020, o calendário acadêmico foi suspenso por prazo indeterminado por meio de Decisão $A d$ Referendum do Conselho Universitário (CONSUNI) (UFAM, 2020a). Interessante destacar que essa suspensão ocorreu uma semana após o início das aulas, trazendo uma situação especialmente desafiadora para todos os atores envolvidos.

Salienta-se ainda que o Ministério da Educação publicou a Portaria n. 343 em 17 de março de 2020, que estabeleceu diretrizes para ampliar a modalidade a distância de forma emergencial, no Ensino Superior (BRASIL, 2020; ARRUDA, 2020).

Em 12 de agosto de 2020, o Ensino Remoto Emergencial (ERE) foi regulamentado pelo Conselho de Ensino, Pesquisa e Extensão (CONSEPE) por meio da Resolução 003/2020. Essa modalidade combina práticas de ensino à distância e presencial, mediada por tecnologias (UFAM, 2020b). A iniciativa ímpar autorizava professores a adotar tecnologias digitais para a interação e construção da sala virtual; mas o regramento não obrigava alunos e professores a aderir compulsoriamente ao modelo de Ensino Remoto. Além disso, permitia aos alunos matriculados no ERE, se fossem reprovados ou evadidos, a cursar a mesma disciplina no presencial, quando tal modalidade retornasse, sem prejuízo ou registro no histórico escolar.

Destaca-se que nem mesmo os professores que já adotavam ambientes on-line nas suas práticas, imaginavam que seria necessária uma mudança tão rápida e emergencial devido à expansão da COVID-19 (MOREIRA; HENRIQUES; BARROS, 2020). É válido ressaltar que a Educação Remota - on-line digital - diferencia-se da Educação a Distância (EaD) pelo caráter emergencial, pois propõe usos e apropriações das tecnologias em circunstâncias específicas de atendimento em que antes existia regularmente a Educação Presencial (ARRUDA, 2020).

Houve muitas dúvidas e preocupações por parte dos professores. Primeiro, as desigualdades que essa modalidade de ensino expõe e amplifica: alunos de baixa renda, atendidos por programas sociais, e que provavelmente não dispunham de sinal de internet de qualidade ou equipamento tecnológico adequado; segundo, porque os discentes estavam acostumados à modalidade de ensino totalmente presencial, inclusive os próprios docentes teriam que aprender novas formas de ensinar e de colocar em movimento diferentes conteúdos curriculares com a mediação tecnológica.

É fundamental que fique muito claro que o objetivo principal naquela ocasião e circunstância não era recriar um ecossistema educacional robusto, mas fornecer acesso 
temporário a estratégias de ensino-aprendizagem de uma maneira que fosse rápida de configurar, simples e confiável de entregar durante essa emergência de saúde (TOMAZINHO, 2020).

Ensinar remotamente não é sinônimo de ensinar a distância, embora esteja diretamente relacionado ao uso de tecnologia e, nesse caso, digital. O Ensino Remoto permite o uso de plataformas já disponíveis e abertas para outros fins, que não sejam estritamente os educacionais, assim como a inserção de ferramentas auxiliares e a introdução de práticas inovadoras (GARCIA et al., 2020).

Considerava-se que a adesão da comunidade ao ERE não seria expressiva, devido aos fatores indicados. De toda forma, não foi o que se observou, pois a solicitação de matrícula foi expressiva para as disciplinas ofertadas. Então, surgiram vários questionamentos a partir de tal momento: como ofertar uma disciplina remota sem reduzir a qualidade do ensino? Que plataforma digital utilizar? Como manter a motivação dos alunos e promover a interação satisfatória?

Para solucionar, pensou-se em um conjunto de soluções: construir a sala virtual em uma plataforma acessível a todos, de fácil ingresso e navegação e, após, adotar práticas de cibercultura (LEVY, 1999) para interação por meio de uso e adequação de aplicativos de tecnologia digital (PIMENTEL, 2019).

A adoção dessas práticas promove uma comunicação mais ágil e dinâmica. Da mesma forma, é potencialmente capaz de incentivar a cooperação, elevar a motivação e estimular o comprometimento entre os alunos. A afetividade é construída na relação entre professor e aluno, mas na atenção dispensada e na eficiência das respostas e não nas mensagens calorosas que possam existir. Constrói-se mais no respeito e no feedback oportuno, demonstrando seriedade e despertando interesse e envolvimento (FARIAS; DIAS, 2010; SANTOS; CARVALHO; PIMENTEL, 2016; MARTINS; BATISTA, 2018).

Por isso, o objetivo deste trabalho foi relatar a experiência vivenciada por professores a partir da adoção do Ensino Remoto e das estratégias pedagógicas adotadas que combinaram o uso de metodologias ativas nas aulas síncronas, a utilização e adequações de recursos de Educação a Distância, assim como a adoção de aplicativo de mensagens nas interações em tempo real.

\subsection{Educação On-line}

A Educação On-line comporta, em conjunto, o ensino e a aprendizagem on-line. Essa modalidade vem sendo aprimorada há muito tempo por meio de pesquisas, proposições de modelos, perspectivas e teorias que possibilitem a construção de um design de curso eficiente, satisfatório e que atenda as necessidades de aprendizagem dos alunos (HODGES et al., 2020).

No processo de planejamento do curso, estão inseridas decisões que impactam na qualidade da oferta por meio do design com dimensões envolvidas que influenciam diretamente no resultado. Para Means, Bakia e Murphy (2014), a complexidade do design requer atenção especial e apreciação de nove dimensões a serem consideradas: modalidade, ritmo, proporção 
aluno-professor, pedagogia, papel do professor on-line, papel do aluno on-line, sincronia da comunicação on-line, papel das avaliações on-line e fonte de feedback.

$\mathrm{Na}$ Educação On-line, o docente atua como um facilitador entre o aluno e o conhecimento por meio da adoção das tecnologias digitais e suas implementações, mas também por intermédio de processos pedagógicos diferenciados e assertivos. Essas práticas fomentam a autonomia discente e podem conduzir ao ambiente de afetividade nas relações, em vistas a promover a colaboração, o sentimento de pertencimento e a autoestima (LEVY, 1999; SANTOS, 2010; DUTRA; SITOIE, 2020).

Essa mediação, portanto, deve propiciar interatividade entre os atores, além de "uma postura participativa, com discussão que aprofunde e amplie o conteúdo proposto, que amplie a visão crítica, que articule a construção do conhecimento a partir do diálogo com todos" (SANTOS; CARVALHO; PIMENTEL, 2016, p. 39).

Por tudo isso, não se resume apenas ao uso maciço de tecnologias digitais de interação em tempo real ou não, mas numa mudança de paradigma dos processos que interferem e promovem a aprendizagem, retirando do docente a condição de sujeito ativo transmissor do conhecimento.

\subsection{Modalidade Ensino Remoto Emergencial}

O Ensino Remoto Emergencial (ERE) foi a modalidade de ensino adotada durante a pandemia da COVID-19, a qual forçou escolas e universidades a paralisarem suas atividades presenciais a fim de promover o distanciamento social. Essa modalidade pode ser adotada eventualmente em casos de crise ou desastre, e parte do princípio de que alunos e professores estão em pontos remotos e distintos (ARRUDA, 2020; MOREIRA; SCHLEMMER, 2020).

$\mathrm{O}$ ERE, entretanto, tem profundas diferenças em relação à modalidade de Educação a Distância (EaD), porque possui concepções e adaptações que o distingue das dimensões políticas, sociais e educacionais da EaD (WILLIAMSON; EYNON; POTTER, 2020). O Ensino Remoto pode, por exemplo, adotar plataformas e softwares não necessariamente concebidos para fins educacionais, mas que possam ser adaptados para o momento e possibilitem interação e aprendizado (GARCIA et al., 2020).

As aulas durante o ERE ocorrem de forma síncrona e assíncrona também; no entanto, as aulas mediadas por tecnologias - remotas e síncronas - fomentaram transformações no "modo de planejar, desenvolver e avaliar as atividades de aula no ERE, contemplando pontos fundamentais, por meio do diálogo" (OLIVEIRA; CORRÊA; MORÉS, 2020, p. 15).

Então, naquele momento pandêmico, o Ensino Remoto Emergencial foi o catalisador da transformação cultural, ainda que incipiente, nos processos educacionais e poderá atingir crescimento substancial na formação e atualização docente e uso das tecnologias digitais com recursos e investimentos representativos e necessários (SOUZA et al., 2020).

Ainda que o ERE seja interessante para manter alunos ativos, observa-se ser importante atentar para as condições socioeconômicas destes, pois os benefícios e dificuldades resultantes da modalidade são diversos e envolvem desde a fragilidade do sinal de transmissão até o acesso a equipamentos tecnológicos (SALVAGNI; WOJCICHOSKI; GUERIN, 2020; SILVA; OLIVEIRA; MONTANARI, 2020). 


\section{PROCEDIMENTOS METODOLÓGICOS}

Esta pesquisa foi desenvolvida para avaliar os resultados obtidos a partir da adoção do ERE na UFAM, bem como apresentar as adequações tecnológicas adotadas e a percepção dos alunos matriculados nas disciplinas de Administração de Recursos Humanos II, Administração Ambiental e Administração Financeira Pública, componentes da matriz curricular do curso de Administração da FES-UFAM.

As disciplinas foram ofertadas por intermédio do Google Classroom, aplicativo conhecido como Sala de Aula, com aulas síncronas mediadas pelo Google Meet. O planejamento dessas aulas oscilou em torno de $40 \%$ a $50 \%$ da carga horária matricial; entretanto também foram adotados grupos de WhatsApp com o intuito de se atingir uma comunicação mais rápida e eficiente entre os alunos.

No que concerne às aulas síncronas, estas são transmitidas em tempo instantâneo por sistemas de webconferências, as chamadas lives, que permitem que professores e alunos tenham condições de realizar interações e organizarem seus tempos de aprendizagem da forma mais próxima à Educação Presencial (ARRUDA, 2020).

A pesquisa foi classificada como de caráter quali-quantitativo, pois uma abordagem não anula a outra, mas se complementam (VÍCTORA; KNAUTH; HASSEN, 2000; ZANELLA, 2013) com a adoção de estatística descritiva para reproduzir os fenômenos observados. A pesquisa também foi considerada de natureza aplicada, contendo embasamento em técnicas bibliográficas e documentais (GIL, 2008).

Quanto ao método, a pesquisa foi classificada como um estudo de múltiplos casos, por serem disciplinas e planejamentos diferentes, ainda que com formato e estrutura semelhantes, já que, segundo Yin (2015), os estudos de caso podem ser manifestos em duas variações: para uma única unidade ou para múltiplas.

As análises quantitativas foram realizadas com base em estatística descritiva adotando os indicadores de rendimentos coletados do Sistema e-campus da UFAM ${ }^{4}$. As informações extraídas foram do número de alunos matriculados - total de 248 nas 3 disciplinas -, incluindo os aprovados, reprovados e evadidos nas ofertas do ERE e do período 2019/1 - primeiro período do ano de 2019 - a fim de que fosse possível realizar comparação entre os resultados. Vale ressaltar que nas duas ofertas - ERE e 2019/1 - os professores ministrantes das disciplinas listadas foram os mesmos.

Também foi realizada uma análise qualitativa baseada na análise de conteúdo do discurso (BARDIN, 2016), e elaborou-se uma nuvem de palavras - construída no site Word Clouds - dos depoimentos dos alunos nos fóruns de discussão, nas salas virtuais, assim como dos registros de interações encontrados nos grupos de WhatsApp das disciplinas, com o intuito de identificar o afloramento da afetividade, a elevação dos níveis motivacionais e o despertar da cooperação, embora não tenham sido mensurados no presente trabalho.

\footnotetext{
${ }^{4}$ Sistema Informatizado da Universidade Federal do Amazonas que registra a vida acadêmica do aluno, desde o ingresso até a saída.
} 


\section{RESULTADOS E DISCUSSÃO}

As salas das disciplinas foram elaboradas na plataforma Google por meio do aplicativo Classroom no domínio da Universidade Federal do Amazonas, uma vez que o professor detinha autonomia de construção, não dependendo de apoio institucional para a sua criação e configuração. Essa atitude reduziu a sobrecarga sobre o Centro de Tecnologia da Informação e Comunicação (CTIC), órgão da UFAM responsável pela área de informática.

As salas foram estruturadas em tópicos que continham a ementa distribuída em unidades. Foram disponibilizados podcasts e vídeos produzidos pelos professores - ou obtidos no YouTube -, artigos de periódicos e capítulos de livros, bem como textos e resenhas, lista de exercícios e orientações para cumprimento de atividades pontuadas ou não. Da mesma forma, foi ainda apresentado o plano de ensino, a proposta de um cronograma de aulas síncronas mediadas pelo Google Meet, um calendário para o cumprimento e postagem das atividades propostas e um fôlder com a síntese do curriculum lattes dos professores.

Em cada tópico, um fórum de discussão permitia a interação tanto com o professor quanto com os colegas, esclarecendo dúvidas em momentos assíncronos. Nesses fóruns, eram solicitadas, também, as impressões acerca do conteúdo, da sala, da estratégia e de todas as relações que envolviam a turma. Tais impressões ficavam então registradas em comentários públicos.

Os alunos foram convidados por cada professor a matricular-se na sala por meio de envio em mala direta; mas somente os que haviam efetivado a matrícula no Sistema e-campus, que é a plataforma oficial da UFAM para este fim. Logo, toda a comunicação contendo o envio de link do Google Meet para o ingresso na reunião que possibilitaria a aula síncrona, assim como outras informações necessárias, eram encaminhadas por e-mail e disponibilizadas no mural da sala.

Apesar disso, observou-se que os alunos não atentavam para essas comunicações, pois o tempo de resposta demorava além do esperado, o que poderia prejudicar a programação, desmotivar os mais ágeis e interferir no rendimento dos demais. Da mesma forma, as interações nos fóruns não estavam ocorrendo a contento, porque os alunos, todos oriundos do Ensino Presencial, não tinham hábito de estudos na modalidade remota ou a distância.

Para solucionar esse problema e promover uma comunicação mais rápida e interativa, pensou-se em adotar algum aplicativo que fosse acessível a todos. Por isso, o WhatsApp pareceu ser o mais interessante, uma vez que existem no Brasil mais de 230 milhões de smartphones ativos (ÉPOCA NEGÓCIOS, 2019).

Essas práticas de cibercultura (LEVY, 1999) complementam a recursividade da modalidade a distância em ofertas que tentam distanciar-se do modelo de educação massiva e conteudista (BELLONI, 2012). Também podem fomentar comportamentos que produzem cooperação e afetividade, pois o feedback é mais rápido do que nas plataformas dos Ambientes Virtuais de Ensino e Aprendizagem (AVEA) e esses vínculos afetivos ficam mais expressos quando confiados e depositados ao docente presente, comunicativo e altruísta (MARTINS; BATISTA, 2018).

Salienta-se que, no Ensino Remoto, o estudante terá de ser gradativa e continuamente incentivado e provocado para a aprendizagem (GARCIA et al., 2020). Sob esse prisma, por intermédio do WhatsApp, os alunos esclareciam dúvidas diversas sobre o conteúdo de uma aula ou avaliação on-line, por exemplo. Ainda eram comunicados acerca dos prazos de postagem de 
atividades ou lembrados sobre as aulas síncronas. Mesmo recebendo o link das reuniões por email, os professores também o disponibilizava nesse ambiente. 0 retorno às demandas dos alunos era rápido e esclarecedor, embora não fosse completo, porque era necessário complementar com o uso de outros recursos da modalidade para se atingir o objetivo da oferta Figura 1.

Figura 1: Captura de tela dos grupos de WhatsApp adotados pelos professores das disciplinas para interagir mais rapidamente com os alunos

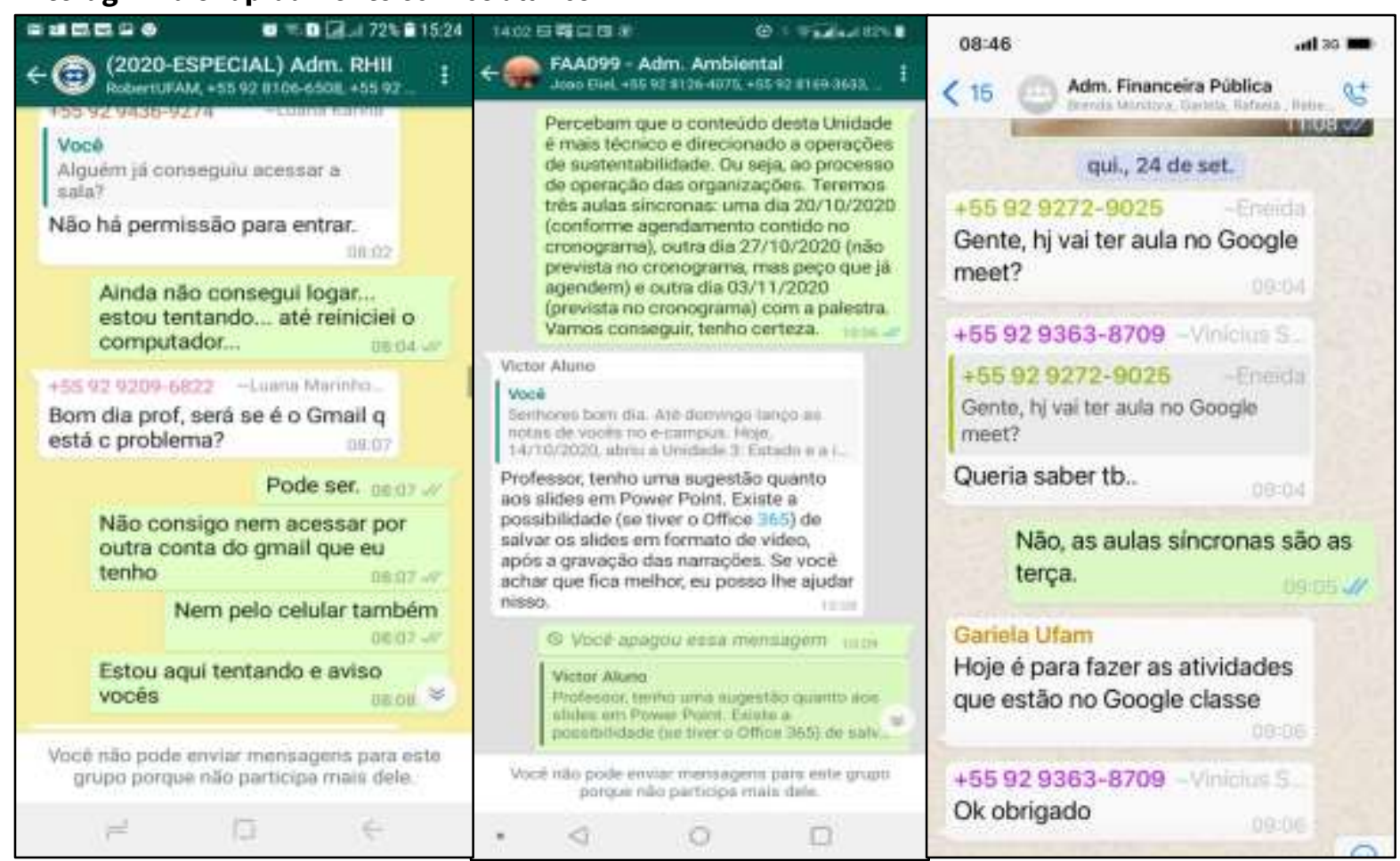

Fonte: WhatsApp (2021).

Nesse ambiente, a colaboração foi propícia entre os alunos, que respondiam a questionamentos dos colegas imediatamente via grupo de WhatsApp quando o professor ainda não havia percebido a dúvida; no entanto, havia sugestões também. Estas auxiliavam na instrumentação digital. Houve, assim, um aprendizado coletivo, pois os alunos ensinavam os professores na adoção das tecnologias e na orientação e estrutura da sala, assim como na composição e sequência de conteúdo e recursos, o que poderia ser caracterizado como o aprender fazendo (AMARAL, 2016). Esse feedback dos alunos foi salutar para construir um cenário de aprendizagem circular e só pôde ser observado graças à interação via WhatsApp - Figura 1.

Ressalta-se que a utilização do ensino remoto envolve decisões quanto à escolha do método de apresentação do conteúdo, à manutenção da atenção, ao interesse e à motivação do aluno e aos resultados da aprendizagem (GARCIA et al., 2020).

Observou-se ainda o interesse dos alunos em ajudar uns aos outros em momentos de atividades que tinham teor colaborativo. 0 compartilhamento dos saberes e dos aprendizados fluiu sem competição, o que pode ter auxiliado nos índices motivacionais, pois o ensino à distância "é um conceito novo de solução para questões pedagógicas intrigantes, como o trabalho cooperativo, a autonomia e a responsabilidade" (FARIAS; DIAS, 2010). 


\section{EmRede}

Esse sentimento promovido pela interação pode ser observado no depoimento dos alunos nos fóruns, onde foram registradas suas impressões acerca da oferta. Nesse espaço foram coletadas críticas, sugestões e elogios à modalidade, instrumentação e ao comportamento dos envolvidos (Figura 2).

Figura 2: Nuvem de palavras obtida a partir do depoimento dos alunos nos fóruns das salas de aula virtuais

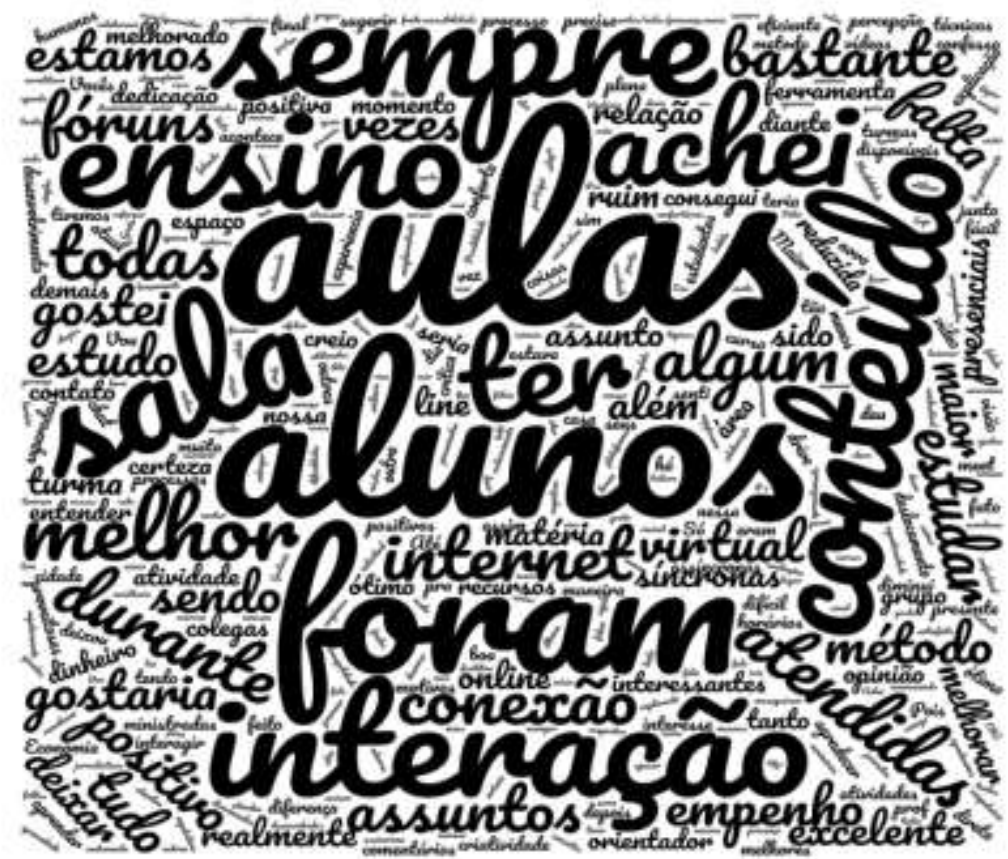

Fonte: Google Classroom (2021).

A Figura 2 destaca, em diversos tamanhos, as palavras mais encontradas nos depoimentos. De maneira decrescente de destaque percebem-se: aulas, alunos, interação, conteúdo, ensino, sala, sempre, melhor, atendidas, internet, método, bastante, assuntos, conexão, empenho, fóruns, virtual, positivo.

Ainda que com problemas de conexão, resultante da baixa qualidade do sinal de internet, os alunos afirmaram que suas expectativas foram atendidas. As salas foram bem elaboradas com conteúdos dispostos adequadamente. Os estudantes também sinalizaram que o empenho dos professores e o envolvimento dos colegas foram bastante positivos. Dentre os recursos da ferramenta Classroom, os fóruns, de certa forma, demonstraram ser um ambiente de interação virtual que auxiliou na promoção do ensino e aprendizagem, como observado no depoimento dos alunos 7, 28 e 34 :

A minha percepção em relação ao desenvolvimento da disciplina foi que em relação às minhas expectativas iniciais, acredito que elas tenham sido sim atendidas. Algo de positivo que pude levar foi o novo entendimento acerca de algumas situações que foram demonstradas [...] (ALUNO 7).

As minhas expectativas foram atendidas pela metodologia adotada. $O$ que achei mais positivo foi a forma de explicação e disponibilização dos materiais pela sala virtual (ALUNO 28). 
Ao orientador, fica a palavra de incentivo, que sua motivação contagiante, seu empenho em ensinar e a criatividade em contornar a situação imposta pela pandemia, sejam luz para tantos outros professores que ainda estão em processo de adaptação (ALUNO 34).

Registraram além das motivações, o lado negativo da modalidade e da interação; entretanto, qualquer que seja a modalidade, há de se observar vantagens e desvantagens. Nesse caso, podem estar muito mais relacionadas às expectativas iniciais dos alunos, que podem ter sido frustradas, em vista da ausência do contato físico como sinalizada pelos alunos 36 e 41:

A interação não é a mesma da sala de aula presencial (ALUNO 36).

Desvantagens: risco de problemas de conexão de internet. Falhas técnicas podem ocorrer ao entregar uma atividade e o contato com o professor diminuiu (ALUNO 41).

Sinto falta de interagir com os colegas e tempo limitado para conversar (ALUNO 30).

Hodges et al. (2000) advertem que muitas instituições podem ter falhado em prover recursos tecnológicos aos estudantes e capacitação aos professores para que pudessem planejar e viabilizar as aulas com condições mínimas para o desenvolvimento e a implementação de um curso on-line de qualidade. Destaca-se que houve alunos da UFAM que não se matricularam no ERE por não ter os recursos tecnológicos para acompanhar as aulas síncronas e assíncronas. Tenente (2020) aponta que no Brasil existem relatos sobre a alta quantidade de estudantes excluídos de acesso on-line pela falta de computadores ou de acesso à internet, bem como sobre a falta de condições adequadas para estudo nas residências e a cronificação da situação socioeconômica das famílias brasileiras. Tais dificuldades destacam a dimensão e a complexidade desse problema.

Tabela 1: Comparativo de indicadores de desempenho escolar para as três disciplinas referente ao ano de 2019 e 2020 nas modalidades presencial e remota

\begin{tabular}{|c|c|c|c|c|}
\hline Disciplina & Indicadores & 2019/1 & 2020/Esp & Variação \\
\hline \multirow{4}{*}{ Adm. Rec. Humanos } & Aprovação & $81,4 \%$ & $79,4 \%$ & $-2,0 \%$ \\
\hline & Reprovação & $5,7 \%$ & $0,0 \%$ & $-5,7 \%$ \\
\hline & Evasão & $12,9 \%$ & $20,6 \%$ & $7,7 \%$ \\
\hline & CoefRend & 7,1 & 7,4 & $4,2 \%$ \\
\hline \multirow{4}{*}{ Adm. Ambiental } & Aprovação & $81,3 \%$ & $92,0 \%$ & $10,7 \%$ \\
\hline & Reprovação & $5,6 \%$ & $6,2 \%$ & $0,6 \%$ \\
\hline & Evasão & $13,1 \%$ & $1,8 \%$ & $-11,3 \%$ \\
\hline & CoefRend & 7,8 & 8,2 & $5,1 \%$ \\
\hline \multirow{4}{*}{ Adm. Financ. Pública } & Aprovação & $74,3 \%$ & $89,7 \%$ & $15,4 \%$ \\
\hline & Reprovação & $7,1 \%$ & $0,0 \%$ & $-7,1 \%$ \\
\hline & Evasão & $18,6 \%$ & $10,3 \%$ & $-8,3 \%$ \\
\hline & CoefRend & 6,1 & 7,8 & $28 \%$ \\
\hline
\end{tabular}

Onde CoefRend = Coeficiente de Rendimento; 2019/1 = Primeiro Período de 2019; 2020/Esp = Período Especial de 2020

Fonte: Sistema e-campus (2021). 
A Tabela 1 apresenta um comparativo entre as ofertas das mesmas disciplinas no ano de 2019 na modalidade presencial, e em 2020, remota. Nota-se que os indicadores de rendimento foram sensivelmente superiores em relação ao presencial, no máximo mantendo-se em estabilidade, com exceção para o coeficiente de rendimento de Administração Financeira Pública que cresceu $28 \%$, bem superior ao das outras disciplinas.

Pode-se inferir pelos resultados apresentados que a modalidade remota não comprometeu o rendimento dos alunos; talvez porque tenha havido interação em tempo real por intermédio do Google Meet - aulas síncronas -, ambiente em que os estudantes podiam sentir-se de certa forma "em sala de aula" presencial, e os contatos, ainda que mediados por tecnologia, ocorriam. Da mesma forma, credita-se aos mesmos desempenhos a comunicação respeitosa e eficaz promovida pelo professor mediante o WhatsApp nas interações, cenário este que promoveu em parte a colaboração e a afetividade entre os atores.

Relativamente à continuidade das aulas na modalidade on-line, os professores precisaram abordar elementos ligados ao cotidiano dos alunos, discutindo inclusive a situação de pandemia vivida, de maneira a explorar a dimensão educativa, pedagógica e científica, assim como instigar motivações que mobilizassem os alunos a aprender em caráter colaborativo - professor-aluno e aluno-aluno. Nesse sentido, o aluno precisou assumir um papel ativo, proativo e protagonista em relação às aulas, haja vista que, assim, poderia realizá-las de modo mais autônomo, quanto ao seu processo de aprendizagem (OLIVEIRA; CORRÊA; MORÉS, 2020).

É possível, ainda, que as impressões dos alunos registradas nos fóruns de discussão tenham impulsionado uma sensível melhoria nos indicadores de rendimento dos demais aprovação, reprovação, evasão e coeficiente da turma. A sensibilidade ao momento de pandemia da COVID-19 e o imperativo da modalidade remota combinados com as inserções de tecnologias digitais podem ter funcionado como alavanca motivacional quando comparados com os resultados obtidos em oferta presencial no ano de 2019.

De forma emergencial, com pouco tempo de planejamento e discussão - o que levaria meses em situação normal -, professores e gestores escolares da Educação Superior, pública ou privada, tiveram que adaptar in real time, isto é, em tempo real, o currículo, as atividades, os conteúdos e as aulas como um todo, as quais foram projetadas para uma experiência pessoal e presencial - mesmo que semipresencial -, e transformá-las em um Ensino Remoto Emergencial totalmente experimental. Fazendo um recorte desse processo, pode-se afirmar que nunca a educação foi tão inovadora. Foi a transformação digital mais rápida que se tem notícia num setor inteiro e ao mesmo tempo (TOMAZINHO, 2020).

O Ensino Remoto Emergencial vai contribuir de forma significativa a ser a universidade que sempre se sonhou e nunca se pensou ser possível construí-la. Uma instituição que experimenta, que aprende, que inova, que tenta o novo e sempre busca o melhor para o ator mais importante desse processo, que é a razão das instituições de Ensino Superior existirem: o aluno e seu ganho de aprendizagem (TOMAZINHO, 2020). 
O objetivo deste trabalho foi relatar a experiência vivenciada por três professores do curso de Administração da Universidade Federal do Amazonas que utilizaram estratégias de abordagens similares durante a oferta de disciplinas na modalidade de Ensino Remoto Emergencial.

Os alunos expressavam certo sentimento de solidão; dificuldade para desenvolver atividades em pequenos grupos; a preocupação com a manutenção da qualidade e, a apreensão associada a problemas de conexão. Ademais, docentes com um letramento digital incipiente e com uma cegueira acerca de estratégicas didáticas que precisaram de apoio e ajuda no desenvolvimento de habilidades para trabalhar e ensinar num ambiente on-line, com sala de aula virtual e aulas síncronas. Além disso, não se pode ignorar as impossibilidades de acesso ligadas às enormes diferenças socioeconômicas entre a população da região norte.

Foi identificado um ambiente de cooperação e solidariedade entre os discentes, muitos relatos positivos quanto aos docentes e expectativas atendidas. Observou-se também um elevado índice de aprovação.

É certo que, as Tecnologias Digitais da Informação e Comunicação (TDIC) como única solução para os dilemas da educação estão longe de ser verdade, mas sem dúvidas poderão indicar caminhos possíveis para práticas mais colaborativas e relações mais horizontais entre professores e alunos no Ensino Superior - tanto neste momento pandêmico como quando tudo passar e iniciar o que muitos vêm chamando de "o novo normal". Afinal, como há tempos já nos ensinou Paulo Freire (1996), a educação é sempre histórica, localizada e deve contribuir para que os aprendizes - professores e alunos - assumam-se como seres sociais e históricos, como seres pensantes, transformadores, criadores e realizadores de sonhos.

Salienta-se a importância de observar as limitações dos achados desta pesquisa, que precisam ser vistos com cautela, uma vez que o grupo de alunos pesquisados é pequeno. Além disso, um mesmo fenômeno pode ser analisado sob diferentes ângulos.

O novo semestre ainda será enfrentado com muitas incertezas, incluindo a de quando será possível retomar as atividades presenciais e com que quantidade de pessoas nos campi (AMARAL; POLYDORO, 2020). Espera-se que, após a pandemia, as universidades fiquem mais fortes, mais solidárias, busquem inovações e mudanças; da mesma forma, que as atividades remotas possam ser mais bem utilizadas quando do retorno às atividades presenciais. $O$ trabalho remoto pode $\mathrm{e}$ deve ser utilizado mais largamente na busca de uma maior produtividade.

\section{REFERÊNCIAS}

AMARAL, E.; POLYDORO, S. Os desafios da mudança para o ensino remoto emergencial na graduação na UNICAMP - Brasil. Linha Mestra, Campinas, n. 41a, p. 52-62, set. 2020. Disponível em: http://lm.alb.org.br/index.php/lm/article/view/392. Acesso em: 12 jan. 2021.

AMARAL, M. M. Autorias textuais e imagética em redes de aprendizagem online: produções docentes e discentes. Novas Edições Acadêmicas, 2016. 
ARRUDA, E. P. Educação remota emergencial: elementos para políticas públicas na educação brasileira em tempos de Covid-19. Em Rede-Revista de Educação a Distância, Porto Alegre, v. 7, n. 1, p. 257-275, 2020. Disponível em: https://www.aunirede.org.br/revista/index.php/emrede/article/view/621. Acesso em: 08 set. 2020.

BARDIN, L. Análise de Conteúdo. São Paulo: Edições 70, 2016.

BELLONI, M. L. Educação a distância. 6. ed. Campinas: Autores Associados, 2012.

BRASIL. Ministério da Educação. Portaria n. 343, de 17 de março de 2020. Dispõe sobre a substituição de aulas presenciais por aulas em meios digitais enquanto durar a situação de pandemia do Novo Coronavírus - COVID-19. Diário Oficial da União: seção 1, Brasília, DF, n. 53, p. 39, 18 mar. 2020. Disponível em: http://www.in.gov.br/en/web/dou/-/portaria-n-343-de-17-de-marco-de-2020-248564376. Acesso em: 14 fev. 2021.

DUTRA, J. M.; SITOIE, C. L. O Ensino a Distância em Tempos de Pandemia e suas Adequações, Interações, Afetividades e Resultados. EaD em Foco, Rio de Janeiro, v. 10, n. 3, e1085, 2020. Disponível em: https://eademfoco.cecierj.edu.br/index.php/Revista/article/view/1085. Acesso em: 12 jan. 2021.

ÉPOCA NEGÓCIOS. Brasil tem 230 milhões de smartphones em uso. 2019. Disponível em: https://epocanegocios.globo.com/Tecnologia/noticia/2019/04/brasil-tem-230-milhoes-de-smartphonesem-uso.html. Acesso em: 12 jan. 2021.

FARIAS, F. R.; DIAS, M. J. Os desafios entre o ensino presencial e o ensino a distância: uma questão de cultura digital e de formação do educador. EAD em Foco, Rio de Janeiro, v. 1, n. 1, abr./out. 2010. Disponível em: https://eademfoco.cecierj.edu.br/index.php/Revista/article/view/9. Acesso em: 12 jan. 2021.

FREIRE, P. Pedagogia da autonomia: saberes necessários à prática educativa. 34. ed. São Paulo: Paz e Terra, 1996.

GARCIA, T. C. M. et al. Ensino remoto emergencial: proposta de design para organização de aula [recurso eletrônico]. Natal: SEDIS/UFRN, 2020. Disponível em: https://repositorio.ufrn.br/handle/123456789/29767. Acesso em: 12 jan. 2021.

GIL, A. C. Métodos e técnicas de pesquisa social. 6. ed. São Paulo: Atlas, 2008.

HODGES, C. et al. The difference between emergency remote teaching and online learning. EDUCAUSE Review. 27 mar. 2020. Disponível em: https://er.educause.edu/articles/2020/3/the-difference-betweenemergency-remote-teaching-and-online-learning. Acesso em: 18 nov. 2021.

LÉVY, P. Cibercultura. São Paulo: Editora 34, 1999.

MARTINS, V.; BAPTISTA, A. A afetividade na Educação Online: percursos e possibilidades. EaD em FOCO, Rio de Janeiro, v. 8, n. 1, p. e639, 2018. Disponível em:

https://eademfoco.cecierj.edu.br/index.php/Revista/article/view/639. Acesso em: 18 mai. 2021.

MEANS, B.; BAKIA, M.; MURPHY, R. Learning Online: What Research Tells Us about Whether,When and How. New York: Routledge, 2014.

MOREIRA, J. A. M.; HENRIQUES, S.; BARROS, D. Transitando de um ensino remoto emergencial para uma educação digital em rede, em tempos de pandemia. Dialogia, São Paulo, n. 34, p. 351-364, jan./abr. 2020. Disponível em: https://doi.org/10.5585/Dialogia.N34.17123. Acesso em: 12 dez. 2020. 
MOREIRA, A.; SCHLEMMER, E. Por um novo conceito e paradigma de educação digital onlife. Revista UFG, Goiânia, v. 20, n. 26, 2020. Disponível em: https://www.revistas.ufg.br/revistaufg/article/view/63438. Acesso em: 01 dez. 2020.

OLIVEIRA, R. M.; CORRÊA, Y.; MORÉS, A. Ensino remoto emergencial em tempos de covid-19: formação docente e tecnologias digitais. Revista Internacional De Formação De Professores, Itapetininga, v. 5 , e020028, p. 1-18, 2020. Disponível em:

https://periodicoscientificos.itp.ifsp.edu.br/index.php/rifp/article/view/179/110. Acesso em: 01 dez. 2020.

ORGANIZAÇÃO PAN-AMERICANA DE SAÚDE (OPAS). Folha informativa sobre COVID-19. 2020. Disponível em:

https://www.paho.org/bra/index.php?option=com_content\&view=article\&id=6101:covid19\&ltemid=875. Acesso em: 16 jun. 2020.

PIMENTEL, M. Princípios do Desenho Didático da Educação Online. Revista Docência e Cibercultura, Rio de Janeiro, v. 2, n. 3, p. 33-53, jan. 2019. Disponível em: https://www.e-publicacoes.uerj.br/index.php/redoc/article/view/36409. Acesso em: 16 jun. 2020.

SALVAGNI, J.; WOJCICHOSKI, N.; GUERIN, M. Desafios à implementação do ensino remoto no ensino superior brasileiro em um contexto de pandemia. Educação Por Escrito, Porto Alegre, v. 11, n. 2, p. e38898, nov. 2020. Disponível em:

https://revistaseletronicas.pucrs.br/ojs/index.php/porescrito/article/view/38898. Acesso em: 16 jun. 2020.

SANTOS, E. Educação online para além da EAD: um fenômeno da cibercultura. In: SILVA, M.; PESCE, L.; ZUIN, A. (Org.). Educação online: cenário, formação e questões didático-metodológicas. Rio de Janeiro: Wak Ed, 2010.

SANTOS, E. O.; CARVALHO, F. S. P.; PIMENTEL, M. Mediação docente online para colaboração: notas de uma pesquisa-formação na cibercultura. ETD: Educação Temática Digital, Campinas, v. 18, n. 1, p. 23-42, 2016. Disponível em: https://periodicos.sbu.unicamp.br/ojs/index.php/etd/article/view/8640749. Acesso em: 16 jun. 2020.

SARAIVA, K.; TRAVERSINI, C.; LOCKMANN, K. A educação em tempos de COVID-19: ensino remoto e exaustão docente. Práxis Educativa, Ponta Grossa, v. 15, e2016289, p. 1-24, 2020. Disponível em: https://revistas2.uepg.br/index.php/praxiseducativa/article/download/16289/209209213529/. Acesso em: 03 nov. 2020.

SILVA, T. C.; OLIVEIRA, E. R.; MONTANARI, R. Difficulties of remote education in rural schools in northern Minas Gerais during the Covid-19 pandemic. Research, Society and Development, [S. I.], v. 9, n. 8, p. e651986053, 2020. Disponível em: https://rsdjournal.org/index.php/rsd/article/view/6053. Acesso em: 15 dez. 2020.

SOUZA, S. M. F. et al. Os encontros e desencontros do ensino presencial, a distância e remoto em tempos de Covid-19. Revista Transformar, 2020. Disponível em:

http://www.fsj.edu.br/transformar/index.php/transformar/article/view/374. Acesso em: 15 dez. 2020.

TENENTE, L. Sem Internet, merenda e lugar para estudar: Veja obstáculos do ensino a distância na rede pública durante a pandemia de COVID-19. 2020. Disponível em:

https://g1.globo.com/educacao/noticia/2020/05/05/sem-internet-merenda-e-lugar-para-estudar-vejaobstaculos-do-ensino-a-distancia-na-rede-publica-durante-a-pandemia-de-covid-19.ghtml. Acesso em: 15 dez. 2020. 
TOMAZINHO, P. Ensino Remoto Emergencial: a oportunidade da escola criar, experimentar, inovar e se reinventar. 2020. Disponível em: https://www.sinepe-rs.org.br/noticias/ensino-remoto-emergencial-aoportunidade-da-escola-criar-experimentar-inovar-e-se-reinventar. Acesso em: 18 jan. 2021.

UNIVERSIDADE FEDERAL DO AMAZONAS (UFAM). Portaria $\mathbf{n}^{\circ} \mathbf{6 2 6}$, de 13 de março de 2020. Sistema Eletrônico de Informação/UFAM. Manaus: UFAM, 2020a. Disponível em: https://edoc.ufam.edu.br/bitstream/123456789/3061/1/SEI_23105.010531_2020_90.pdf. Acesso em: 14 fev. 2021.

UNIVERSIDADE FEDERAL DO AMAZONAS (UFAM). Resolução $\mathbf{n}^{\circ} \mathbf{0 0 3}$, de $\mathbf{1 2}$ de agosto de 2020. Aprova o Regulamento do Ensino Remoto Emergencial (ERE), e o Calendário Acadêmico Especial 2020, no âmbito do ensino de graduação da UFAM. Manaus: UFAM, 2020b. Disponível em:

https://edoc.ufam.edu.br/bitstream/123456789/3497/1/SEI_UFAM\%20-\%200276638\%20-

\%20Resoluc\%cc\%a7a\%cc\%830_0032020_CONSEPE_ERE.pdf. Acesso em: 14 fev. 2021.

VÍCTORA, C. G.; KNAUTH, D. R.; HASSEN, M. N. A. Metodologias qualitativa e quantitativa. In: VíCTORA, C. G.; KNAUTH, D. R.; HASSEN, M. N. A. Pesquisa Qualitativa em Saúde: uma introdução ao tema. Porto Alegre: Tomo Editorial, 2000.

WILLIAMSON, B.; EYNON, R.; POTTER, J. Pandemic politics, pedagogies and practices: digital technologies and distance education during the coronavirus emergency. Learning, Media and Technology, v. 45, n. 2, p. 107-114, 2020. Disponível em: https://www.tandfonline.com/doi/full/10.1080/17439884.2020.1761641. Acesso em: 14 fev. 2021.

YIN, R. K. Estudo de caso: planejamento e métodos. 5. ed. Porto Alegre: Bookman, 2015.

ZANELLA, L. C. H. Metodologia da Pesquisa. 2. ed. Florianópolis: Departamento de Ciências da Administração/UFSC, 2013. 